This item was submitted to Loughborough's Research Repository by the author.

Items in Figshare are protected by copyright, with all rights reserved, unless otherwise indicated.

\title{
Effect of repeated sprints on postprandial endothelial function and triacylglycerol concentrations in adolescent boys
}

PLEASE CITE THE PUBLISHED VERSION

http://dx.doi.org/10.1080/02640414.2014.964749

\section{PUBLISHER}

(C) Taylor and Francis

\section{VERSION}

AM (Accepted Manuscript)

\section{PUBLISHER STATEMENT}

This work is made available according to the conditions of the Creative Commons Attribution-NonCommercialNoDerivatives 4.0 International (CC BY-NC-ND 4.0) licence. Full details of this licence are available at: https://creativecommons.org/licenses/by-nc-nd/4.0/

\section{LICENCE}

CC BY-NC-ND 4.0

\section{REPOSITORY RECORD}

Sedgwick, Matthew J., John G. Morris, Mary Nevill, and Laura A. Barrett. 2019. "Effect of Repeated Sprints on Postprandial Endothelial Function and Triacylglycerol Concentrations in Adolescent Boys". figshare. https://hdl.handle.net/2134/21895. 


\section{Effect of repeated sprints on postprandial endothelial function and triacylglycerol concentrations in adolescent boys}

Short title: Sprint exercise and endothelial function in boys

Matthew J. Sedgwick ${ }^{1}$, John G. Morris ${ }^{2}$, Mary E. Nevill ${ }^{2}$ and Laura A. Barrett ${ }^{1}$

${ }^{1}$ School of Sport, Exercise and Health Sciences, Loughborough University, Loughborough, LE11 3TU, UK

${ }^{2}$ Department of Sport Science, School of Science and Technology, Nottingham Trent University, Nottingham, NG11 8NS, UK

\section{Corresponding author}

Dr. Laura Barrett

School of Sport, Exercise and Health Sciences

Loughborough University

Loughborough

Leicestershire

LE11 3TU

UK.

亩 +441509226395

息 +441509226301

D.A.Barrett@lboro.ac.uk

\section{Author Contribution}

MJS, JGM, MEN and LAB designed the research, MJS and LAB conducted the research, MJS and JGM analysed data, MJS, JGM, MEN and LAB wrote the manuscript and LAB had primary responsibility for final content. All authors read and approved the final manuscript. All authors have no conflicts of interest.

\section{Awknowledgements}

We would like to thank all the boys who participated in the present study along with their parents/guardians/caregivers for their support throughout the study. We would also like to thank the staff at Woodbrook Vale High School, in particular Mr Ian Smith, for their support.

\section{Funding}

The present study received no specific grant from any funding agency in the public, commercial or not-for-profit sectors. 


\title{
Effect of repeated sprints on postprandial endothelial function and triacylglycerol concentrations in adolescent boys
}

\begin{abstract}
This study investigated if repeated, very short duration sprints influenced endothelial function (indicated by flow-mediated dilation) and triacylglycerol concentrations following the ingestion of high-fat meals in adolescent boys. Nine adolescent boys completed two, 2-day main trials (control and exercise), in a counter-balanced, crossover design. Participants were inactive on day 1 of the control trial but completed 40 x 6 s maximal cycle sprints on day 1 of the exercise trial. On day 2 capillary blood samples were collected and flow-mediated dilation measured prior to, and following, ingestion of a high-fat breakfast and lunch. Fasting flow-mediated dilation and plasma triacylglycerol concentration were similar in the control and exercise trial $(P>0.05)$. In the control trial flow-mediated dilation was reduced by $20 \%$ and $27 \%$ following the high-fat breakfast and lunch; following exercise these reductions were negated (main effect trial, $P<0.05$; interaction effect trial $\mathrm{x}$ time, $P<0.05$ ). The total area under the plasma triacylglycerol concentration versus time curve was $13 \%$ lower on day 2 in the exercise trial, compared to the control trial (8.65 (0.97) vs. 9.92 (1.16) $\left.\mathrm{mmol} \cdot \mathrm{L}^{-1} \cdot 6.5 \mathrm{~h}, P<0.05\right)$. These results demonstrate that repeated $6 \mathrm{~s}$ maximal cycle sprints can have beneficial effects on postprandial endothelial function and triacylglycerol concentrations in adolescent boys.
\end{abstract}




\section{Key Words}

Coronary heart disease risk; Flow-mediated dilation; Postprandial lipaemia; Repeated sprint exercise; High-intensity exercise.

\section{Introduction}

There is growing evidence that the ability to prevent or delay the occurrence of atherosclerosis (the underlying cause of coronary heart disease), lies in the maintenance of a low lifetime coronary heart disease risk (Magnussen et al., 2012). As atherosclerosis clearly has its origins in childhood, preventing the development of risk factors in the young and maintaining a low level of coronary heart disease risk in early life would seem essential (Magnussen et al., 2012).

Both endothelial dysfunction (Yeboah et al., 2009) and elevated postprandial triacylglycerol concentrations (Bansal et al., 2009) have been identified as independent risk factors for coronary heart disease. In addition, endothelial dysfunction appears to be a requirement for the initiation and development of atherosclerosis (Juonala et al., 2004) making it a particularly pertinent risk factor to consider in the young. The ingestion of meals containing substantial quantities of fat is common in young people in western societies (Taveras et al., 2005) and ingesting large amounts of fat results in endothelial dysfunction and elevated postprandial triacylglycerol concentrations in both adults (Gill et al., 2004; Tyldum et al., 2009; Wallace, Johnson, Padilla, \& Mather, 2010) and adolescents (Sedgwick et al., 2013). 
Therefore, interventions that reduce endothelial dysfunction or triacylglycerol concentrations postprandially could have important health benefits.

Acute interventions based on exercise have been effective at attenuating endothelial dysfunction or the rise in triacylglycerol concentrations evident after ingestion of meal/s high in fat. A single 30 to 180 min session of moderate-intensity exercise completed 12 to $18 \mathrm{~h}$ prior to the ingestion of a high-fat meal has consistently been shown to lower postprandial triacylglycerol concentrations (Barrett, Morris, Stensel, \& Nevill, 2006; Barrett, Morris, Stensel, \& Nevill, 2007; Gill et al., 2004; Lee, Burns, Kuk, \& Arslanian, 2013; MacEneaney et al., 2009; Petitt \& Cureton, 2003; Sedgwick et al., 2013; Tolfrey et al., 2008; Tolfrey et al., 2012) and more recently to attenuate postprandial endothelial dysfunction in both adults and adolescents (Gill et al., 2004; Sedgwick et al., 2013; Tyldum et al., 2009).

Repeated sprints of relatively long duration (30 s), interspersed with periods of active low-intensity recovery, have also been shown to elicit health benefits in adults (Gibala, Little, MacDonald, \& Hawley, 2012) including reductions in postprandial triacylglycerol concentration (Freese, Levine, Chapman, Hausman, \& Cureton, 2011; Gabriel, Ratkevicius, Gray, Frenneaux, \& Gray, 2012). However, continuous moderate-intensity exercise or long duration sprinting is not typical of young people's activity patterns, which are usually intermittent in nature and characterised by multiple short-duration bouts of vigorous activity typically ( $90 \%$ of bouts) lasting less than 10 s (median duration 4 s) (Stone, Rowlands, \& Eston, 2009). Baquet, Stratton, Van Praagh and Berthoin (2007) have shown that although young people undertake a short duration of vigorous or higher intensity physical activity, 
this vigorous activity contributes to a substantial portion (36\%) of the total volume of activity as indicated by counts (Baquet et al. 2007). It has also been shown that these short bouts of activity can have similar health benefits to longer bouts (Stone, Rowlands, Middlebrooke, Jawis, \& Eston, 2009). Since the young appear to undertake very short bouts of vigorous activity, repeated short-duration $(<10 \mathrm{~s})$ sprints may offer a better and more attractive exercise model for the young.

Barrett and colleagues reported that 90 minutes of games type activity (15 m sprints interspersed with walking, jogging and faster running) reduced postprandial triacylglycerol concentrations in adolescent boys (Barrett et al., 2007) and men (Barrett et al., 2006). It is not possible from these previous studies to establish what the effect of the short sprints alone was on the postprandial triacylglycerol concentrations. As well as being closer to the typical activity pattern of the young, repeated very short sprints may be more practical and better tolerated than the repeated $30 \mathrm{~s}$ sprints shown to induce health benefits in adults (Freese et al., 2011; Gabriel et al., 2012; Gibala et al., 2012), especially as the repeated longer sprints require high levels of motivation to complete and are often associated with feelings of nausea and light-headedness (Richards et al., 2010). Interestingly, children and adolescents report lower ratings of perceived exertion following sprint exercise and demonstrate less fatigue across repeated sprints than adults (Ratel et al., 2006); however, data regarding tolerance to sprint exercise is rarely presented.

The effect of sprint exercise on postprandial endothelial function has not previously been investigated in adults or the young. However, repeated sprints, completed the evening prior to the ingestion of a high-fat meal have been reported to reduce 
postprandial triacylglycerol concentrations (Freese et al., 2011; Gabriel et al., 2012; Tan et al., 2013), and oxidative stress (Gabriel et al., 2012) in adults. As previous research suggests that the high-fat meal induced endothelial dysfunction is a consequence of high postprandial triacylglycerol concentrations and oxidative stress (Wallace et al., 2010), repeated sprint exercise could also have the ability to attenuate postprandial endothelial dysfunction.

Therefore, the purpose of the present study was to investigate the effect of a session of repeated $6 \mathrm{~s}$ sprints on postprandial endothelial function and triacylglycerol concentrations in apparently healthy adolescent boys.

\section{Methods}

\section{Participants}

Fifteen normal weight adolescent boys volunteered to participate in the study, with nine boys completing the study (aged 12.5 to 14.1 years, Tanner Stage 1 to 4 (median 3)). Non-completion of the study was due to a failure to tolerate the exercise $(n=5)$ or a dislike of the blood sampling procedures $(n=1)$. The study was conducted according to the guidelines in the Declaration of Helsinki and all procedures were approved by the Ethics Committee of the institution in which the work was performed. Prior to testing the procedures and risks of participating in the study were explained to the boys. Following this written consent from a parent and written assent from each participant was obtained. Participants were asked to complete a health history questionnaire which indicated that they were apparently 
healthy and not taking any drugs known to affect lipid or carbohydrate metabolism. Participant characteristics are presented in Table 1.

\section{Study Design}

Following preliminary tests participants undertook two, 2-day main trials which were separated by seven days (control trial and exercise trial) in a $2 \times 2$ replicated (7 replicates) Latin square design.

\section{Preliminary Tests}

Body mass was measured to the nearest $0.01 \mathrm{~kg}$ and stature to the nearest $0.1 \mathrm{~cm}$. Skinfold thickness was measured at four sites (biceps, triceps, subscapular and suprailiac) to the nearest $0.2 \mathrm{~mm}$ using calipers (Harpenden, Baty International, England) and waist and hip circumferences were measured to the nearest $0.1 \mathrm{~cm}$ using a non-stretch tape. Each participant undertook a self-assessment of maturity using a five-point scale described by Tanner (Tanner, 1989). Finally each participant was familiarised with the repeated sprint exercise. Participants were asked to warmup, against an air resistance setting of 1 , on a cycle ergometer (Wattbike,

Nottingham, UK). The warm-up consisted of $5 \mathrm{~min}$ cycling at $60 \mathrm{rev} \cdot \mathrm{min}^{-1}, 5 \mathrm{~min}$ stretching, $3 \times 30 \mathrm{~s}$ cycling at $80 \mathrm{rev} \cdot \mathrm{min}^{-1}$ and $2 \times 30 \mathrm{~s}$ cycling at $100 \mathrm{rev} \cdot \mathrm{min}^{-1}$ with $30 \mathrm{~s}$ recovery between sprints. When the warm-up was finished participants were asked to complete 3 x 6 s maximal sprints with 90 s recovery between sprints. Following a 5 min rest participants completed one block of the sprint exercise: $10 \mathrm{x}$ 6 s maximal sprints with 90 s recovery between sprints. 


\section{Main trials}

Participants were asked not to consume supplements in the seven days prior to the main trials. Participants were also asked to refrain from undertaking exercise and to be as physically inactive as possible during the day before (day 0) and throughout each main trial. During this time participants wore an ActiGraph GT1M accelerometer during waking hours to monitor physical activity. The accelerometer was not worn during the repeated sprint exercise protocol. The ActiGraph is a uniaxial electromechanical device that records movement in the vertical plane. The sampling epoch was 5 seconds. During data processing 60 minutes of consecutive zero's was considered indicative of non-wearing and these data were excluded. Minimum day length was set at 9 hours and time spent in low- and moderate- and vigorous-intensity physical activity was calculated using age specific cutpoints (Freedson et al., 1997). In order to standardise their diet participants were asked to complete a food diary for day 0 and day 1 of the first main trial and were then asked to replicate this diet for the subsequent trial.

On day 1 of the control trial participants were asked to be physically inactive; whereas in day 1 of the exercise trial they were asked to be physically inactive until 15:30 when they reported to the laboratory to complete a warm up and four blocks of 10 x 6 s sprints (as described above). Each block was separated by 3 min of rest. Heart rate was recorded during the last sprint and the $90 \mathrm{~s}$ recovery period following each block. Ratings of perceived exertion (Borg, 1973) were assessed following the 
last sprint of each block and participants were requested to give a rating that was representative of their perceived exertion over the whole block of exercise.

On day 2 of each main trial following an overnight fast participants reported to the laboratory at 08:00, where flow-mediated dilation was assessed and a capillary blood sample collected. Participants were then given breakfast and a clock was started when participants took their first mouthful of the meal. After breakfast participants

rested for $6.5 \mathrm{~h}$. Participants were provided with lunch at $3.5 \mathrm{~h}$. Further measures of flow-mediated dilation were undertaken at 3 and $6.5 \mathrm{~h}$ and additional blood samples were collected at $0.5,1,3,4,4.5$ and $6.5 \mathrm{~h}$.

\section{Meals}

Breakfast consisted of croissant, chocolate spread and a chocolate milkshake (chocolate power, whole-fat milk and double cream). Lunch consisted of a cheese sandwich, (white bread, butter and cheese), ready salted crisps and a chocolate milkshake (chocolate powder and whole-fat milk). Participants were given $15 \mathrm{~min}$ to consume breakfast and $20 \mathrm{~min}$ to consume lunch. Breakfast provided participants with $1.5 \mathrm{~g}$ fat (60\%), $1.8 \mathrm{~g}$ carbohydrate $(33 \%), 0.4 \mathrm{~g}$ protein $(7 \%)$ and $92.9 \mathrm{~kJ}$ per kilogram body mass and lunch provided participants with $1.1 \mathrm{~g}$ fat (50\%), $1.9 \mathrm{~g}$ carbohydrate (37\%), $0.6 \mathrm{~g}$ protein $(13 \%)$ and $84.6 \mathrm{~kJ}$ per kilogram of body mass. Participants consumed water ad libitum during the first trial and in the subsequent trial this intake was replicated. 


\section{Endothelial function assessment by flow-mediated dilation}

Flow-mediated dilation measurements were made using previously published guidelines and recommendations and have been described in detail elsewhere (Sedgwick et al., 2013). Briefly; the brachial artery was imaged longitudinally in the distal third of the upper, right arm using ultrasound (11 MHz linear array transducer, attached to a high-resolution ultrasound machine Power Vision 6000, Toshiba, Tochigi, Japan). Pulsed wave Doppler was used, simultaneously with B-mode imaging, to assess blood flow velocity. Following 20 min of supine rest, a basal scan of the artery was conducted over 20 consecutive cardiac cycles. Then a pneumatic, rapid inflating blood pressure cuff (Hokanson, WA, USA), positioned immediately distal to the anticubital fossa, was inflated to $200 \mathrm{mmHg}$ for $5 \mathrm{~min}$. Further images were captured continuously from $30 \mathrm{~s}$ before to $3 \mathrm{~min}$ after cuff release. All images were captured on the r-wave of the cardiac cycle.

Digitisation of recorded images was undertaken using specialised edge-detection and wall-tracking software (Brachial analyzer, version 4.1.3; Medical Imaging Applications LLC, Iowa City, IA). Flow-mediated dilation was calculated as the percentage change from basal diameter to peak diameter, and was also normalised for the post-occlusion shear rate (Harris, Nishiyama, Wray, \& Richardson, 2010).

The coefficient of variation of measurements made seven days apart for fasting basal diameter, peak diameter and flow-mediated dilation in our laboratory was $0.6,1.1$ and $9.7 \%$, and in the postprandial state was $0.8,0.9$ and $10.0 \%$ respectively. The intraobserver coefficient of variation based on repeated analysis of a single scan was 
$0.4 \%$ for basal diameter, $0.3 \%$ for peak diameter and $6.4 \%$ for flow-mediated dilation.

\section{Blood sampling and biochemical analysis}

Capillary blood was taken from a finger on a previously warmed left hand and collected into $500 \mu \mathrm{l}$ potassium-EDTA-coated microvettes (Sarstedt, Leicester, UK). The blood sample was then immediately centrifuged at $1500 \mathrm{x} \mathrm{g}$ for $10 \mathrm{~min}$ at $4{ }^{\circ} \mathrm{C}$. The resulting plasma was then transferred into microcentrifuge tubes (Sarstedt, Leicester, UK) and stored at $-20{ }^{\circ} \mathrm{C}$ for later analysis. Plasma triacylglycerol and glucose concentration were determined by enzymatic, colorimetric methods (HORIBA ABX Diagnostics, Montpellier, France). Plasma insulin concentration was determined by ELISA (Mercodia, Uppsala, Sweden). Within batch coefficients of variation were: triacylglycerol $0.6 \%$, glucose $0.3 \%$ and insulin $2.9 \%$.

\section{Statistical analysis}

The total and incremental area under the plasma concentration versus time curves for triacylglycerol, glucose and insulin were calculated using the trapezium rule. Insulin resistance was estimated using the homeostatic model assessment of insulin resistance (Matthews et al., 1985). Data was analysed using the PASW statistics software version 18.0 for Windows (SPSS Inc, Chicago, IL). Normality of the residual errors were tested using the Shapiro-Wilk test and where necessary data was logarithmically transformed prior to statistical analysis. Paired Student's t-test were used to compare differences between trials for; total activity counts and time spent in 
low-, moderate- and vigorous-intensity physical activity during day 0 and day 1 of the main trials, fasting basal diameter, peak diameter, flow-mediated dilation, normalised flow-mediated dilation and plasma triacylglycerol, glucose and insulin concentration, areas under the plasma concentration versus time curves and homeostatic model assessment of insulin resistance. A mixed effects general linear model with two fixed factors (trial and time) and one random factor (participant) was used to compare differences between trials over time, and any possible interactions between trial and time, for basal diameter, peak diameter, flow-mediated dilation, normalised flow-mediated dilation and plasma triacylglycerol, glucose and insulin concentration. Where there was a violation of compound symmetry, based on Mauchly's test, the degrees of freedom were adjusted using the Huynh-Feldt epsilon. The Least Significant Difference was used to identify exactly where any main effects of time lay. When a significant trial $\mathrm{x}$ time interaction was revealed targeted pairwise comparisons were used, specifically, comparisons within-trials with respect to the fasting measure and between trials at the same time point. Pearson's correlation coefficient was calculated in the control and in the exercise trial: for fasting plasma triacylglycerol concentration and fasting flow-mediated dilation; for the change in flow-mediated dilation and the total area under the plasma triacylglycerol concentration versus time curve from $0 \mathrm{~h}$ to $3 \mathrm{~h}$; for the change in flow-mediated dilation and the total area under the plasma triacylglycerol concentration versus time curve from $0 \mathrm{~h}$ to $6.5 \mathrm{~h}$; for basal diameter and fasting flow-mediated dilation; for the change in flow-mediated dilation and basal diameter from $0 \mathrm{~h}$ to $3 \mathrm{~h}$; and for the change in flow-mediated dilation and basal diameter from $0 \mathrm{~h}$ to $6.5 \mathrm{~h}$ (twelve correlations in total). Statistical significance was accepted at the $\mathrm{P}<0.05$ level. All participant characteristics are presented as population 
marginal mean and standard deviation (SD) and all experimental data are presented as population marginal mean and standard error of the mean (SEM). In addition, to supplement P-values, absolute standardised effect sizes (ES), mean difference $(\bar{X})$ and $95 \%$ confidence intervals $(95 \% \mathrm{CI})$ for pairwise differences between experimental conditions (calculated using the t-distribution and degrees of freedom $(n-1))$ are presented where applicable.

\section{Results}

\section{Physical activity}

Complete accelerometer data was provided by 7 boys. No differences were observed between trials for total activity counts and time spent in low-, moderate- and vigorous-intensity physical activity, during day 0 or day 1 (Table 2 ; all $P>0.05$ ).

\section{Responses to sprint exercise}

Peak power, mean power, peak cadence and mean cadence during the $6 \mathrm{~s}$ sprints were $472(41) \mathrm{W}, 417(33) \mathrm{W}, 113(3) \mathrm{rev} \cdot \mathrm{min}^{-1}$ and 104 (3) $\mathrm{rev} \cdot \mathrm{min}^{-1}$ respectively. Peak heart rate, mean heart rate and ratings of perceived exertion were 156 (6) beats $\cdot \min ^{-1}, 133(5)$ beats $\cdot \min ^{-1}$ and 12 (1) respectively. The total mechanical work done during each $6 \mathrm{~s}$ sprint was $2.5(0.6) \mathrm{kJ}$ resulting in a total mechanical work done over the 40 sprints of 98.9 (7.9) kJ. The mechanical work done during the warm-up was not recorded. 


\section{Measures in the fasted state}

No differences were observed between trials for fasting basal diameter (Table 3, $P=0.24, \mathrm{ES}=0.13, \bar{X}_{\text {exercise-control }}(95 \% \mathrm{CI})=-0.04(-0.27$ to 0.19$\left.) \mathrm{mm}\right)$, peak diameter (Table 3, $P=0.19, \mathrm{ES}=0.13, \bar{X}_{\text {exercise-control }}(95 \% \mathrm{CI})=-0.06(-0.32$ to 0.21$\left.) \mathrm{mm}\right)$, flowmediated dilation (Figure 1(a), $P=0.48, \mathrm{ES}=0.09, \bar{X}_{\text {exercise-control }}(95 \% \mathrm{CI})=-0.38(-$ 3.42 to 2.65 ) \%), normalised flow-mediated dilation (Figure 1(b), $P=0.23, \mathrm{ES}=0.50$, $\bar{X}_{\text {exercise-control }}(95 \% \mathrm{CI})=-27.7 \times 10^{-6}\left(-175.2 \times 10^{-6}\right.$ to $\left.\left.119.9 \times 10^{-6}\right)\right)$, plasma triacylglycerol concentration (Figure 2(a), $P=0.14, \mathrm{ES}=0.32, \bar{X}_{\text {exercise-control }}(95 \%$ $\mathrm{CI})=-0.07(-0.38$ to 0.24$\left.) \mathrm{mmol} \cdot \mathrm{L}^{-1}\right)$, plasma glucose concentration (Figure 2(b), $P=0.78, \mathrm{ES}=0.05, \bar{X}_{\text {exercise-control }}(95 \% \mathrm{CI})=0.05(-0.49$ to 0.53$\left.) \mathrm{mmol} \cdot \mathrm{L}^{-1}\right)$ and plasma insulin concentration (Figure 2(c), $P=0.07, \mathrm{ES}=0.66, \bar{X}_{\text {exercise-control }}(95 \% \mathrm{CI})=-12.42$ (-53.58 to 28.74$\left.) \mathrm{pmol} \cdot \mathrm{L}^{-1}\right)$. No differences were observed between trials for homeostatic model assessment of insulin resistance (Exercise vs. Control; $1.6(0.2)$ vs. $2.1(0.3), P=0.97, \mathrm{ES}=0.62, \bar{X}_{\text {exercise-control }}(95 \% \mathrm{CI})=-0.5(-2.3$ to 1.3$\left.)\right)$.

Measures in the postprandial state: Basal diameter, peak diameter, flowmediated dilation and normalised flow-mediated dilation.

Basal diameter and peak diameter increased following the ingestion of the high-fat test meals, but did not differ between trials (Table 3; basal diameter: main effect trial, $P=0.21$; main effect time, $P<0.001$; interaction effect trial $\mathrm{x}$ time, $P=0.13$; peak diameter: main effect trial, $P=0.61$; main effect time, $P=0.002$; interaction effect trial $\mathrm{x}$ time, $P=0.052)$. 
Postprandial flow-mediated dilation was lower in the control compared with the exercise trial (Figure 1(a); main effect trial, $P=0.012$; main effect time, $P=0.004$; interaction effect trial $\mathrm{x}$ time, $P=0.003)$. Pairwise comparisons identified that flowmediated dilation was lower compared to the fasting measure at both $3 \mathrm{~h}$ (Figure 1(a), $P=0.003, \mathrm{ES}=0.43, \bar{X}_{\text {control } 3 \mathrm{~h}-\text { control oh }}(95 \% \mathrm{CI})=-1.62(-4.28$ to 1.04$\left.) \%\right)$ and 6.5 h (Figure 1(a), $P=0.003, \mathrm{ES}=0.63, \bar{X}_{\text {control } 6.5 \mathrm{~h}-\text { control } 0 \mathrm{~h}}(95 \% \mathrm{CI})=-2.21(-5.75$ to 1.33) \%) in the control trial only and that flow-mediated dilation was significantly higher in the exercise trial, compared to the control trial, at $3 \mathrm{~h}$ (Figure 1(a), $P=0.002, \mathrm{ES}=0.37, \bar{X}_{\text {exercise-control }}(95 \% \mathrm{CI})=1.41(-0.70$ to 3.52$\left.) \%\right)$ and $6.5 \mathrm{~h}$ (Figure 1(a), $P=0.002, \mathrm{ES}=0.45, \bar{X}_{\text {exercise-control }}(95 \% \mathrm{CI})=1.43(-0.69$ to 3.55$\left.) \%\right)$. Normalised flow-mediated dilation decreased following the ingestion of the high-fat meals, but did not differ between trial (Figure 1(b); main effect trial, $P=0.97$; main effect time, $P=0.001$; interaction effect trial x time, $P=0.08)$.

\section{Measures in the postprandial state: Triacylglycerol, glucose and insulin concentrations}

Postprandial plasma triacylglycerol concentration was lower in the exercise compared to the control trial (Figure 2(a); main effect trial, $P=0.019$; main effect time, $P<0.001$; interaction effect trial $\mathrm{x}$ time, $P=0.07)$. The total area under the plasma triacylglycerol concentration versus time curve was $13 \%$ lower following exercise (Exercise vs. Control: $8.65(0.97)$ vs. 9.92(1.16) $\mathrm{mmol} \cdot \mathrm{L}^{-1} \cdot 6.5 \mathrm{~h}, P=0.023$, $\mathrm{ES}=0.40, \bar{X}_{\text {exercise-control }}(95 \% \mathrm{CI})=-1.27(-4.41$ to -1.87$\left.) \mathrm{mmol} \cdot \mathrm{L}^{-1} \cdot 6.5 \mathrm{~h}\right)$. The incremental area under the plasma triacylglycerol concentration versus time curve was $15 \%$ lower following exercise (Exercise vs. Control: 4.52 (0.61) vs. 5.32 (0.75) 
$\mathrm{mmol} \cdot \mathrm{L}^{-1} \cdot 6.5 \mathrm{~h}, P=0.036, \mathrm{ES}=0.39, \bar{X}_{\text {exercise-control }}(95 \% \mathrm{CI})=-0.79(-2.98$ to 1.40$)$ $\left.\mathrm{mmol} \cdot \mathrm{L}^{-1} \cdot 6.5 \mathrm{~h}\right)$.

Postprandial plasma glucose concentrations did not differ between trials (Figure 2(b); main effect trial, $P=0.12$; main effect time, $P<0.001$; interaction effect trial $\mathrm{x}$ time, $P=0.39$ ). The total area under the plasma glucose concentration versus time curve did not differ between trials (Exercise vs. Control: 42.22 (1.40) vs. 41.13 (0.89) $\mathrm{mmol} \cdot \mathrm{L}^{-1} \cdot 6.5 \mathrm{~h}, P=0.22, \mathrm{ES}=0.31, \bar{X}_{\text {exercise-control }}(95 \% \mathrm{CI})=1.09(-4.62$ to 6.80$)$ $\left.\mathrm{mmol} \cdot \mathrm{L}^{-1} \cdot 6.5 \mathrm{~h}\right)$.

Postprandial plasma insulin concentrations did not differ between trials (Figure 2(c); main effect trial, $P=0.27$; main effect time, $P=0.001$; interaction effect trial $\mathrm{x}$ time, $P=0.49$ ). The total area under the plasma insulin concentration versus time curve did not differ between trials (Exercise vs. Control: 1829.4 (273.0) vs. 1741.8 (224.4) $\mathrm{pmol} \cdot \mathrm{L}^{-1} \cdot 6.5 \mathrm{~h}, P=0.38, \mathrm{ES}=0.12, \bar{X}_{\text {exercise-control }}(95 \% \mathrm{CI})=87.5(-563.1$ to 738.1$)$ $\left.\mathrm{mmol} \cdot \mathrm{L}^{-1} \cdot 6.5 \mathrm{~h}\right)$.

\section{Correlations between flow-mediated dilation and basal diameter and triacylglycerol concentrations}

The correlations between fasting flow-mediated dilation and plasma triacylglycerol concentrations were: Control, $\mathrm{r}=-0.604, P=0.09$; Exercise, $\mathrm{r}=-0.394, P=0.29$. The correlations between the change in flow-mediated dilation and the total area under the plasma triacylglycerol concentration versus time curve from $0 \mathrm{~h}$ to $3 \mathrm{~h}$, were: Control, $\mathrm{r}=0.289, P=0.45$; Exercise, $\mathrm{r}=-0.059, P=0.88$. The correlations between the 
change in flow-mediated dilation and the total area under the plasma triacylglycerol concentration versus time curve from $0 \mathrm{~h}$ to $6.5 \mathrm{~h}$, were: Control, $\mathrm{r}=0.514, P=0.16$; Exercise, $\mathrm{r}=0.210, P=0.59$.

The correlations between fasting flow-mediated dilation and basal diameter were: Control, $\mathrm{r}=0.164, P=0.67$; Exercise, $\mathrm{r}=0.371, P=0.33$. The correlations between the change in flow-mediated dilation and basal diameter from $0 \mathrm{~h}$ to $3 \mathrm{~h}$, were: Control, $\mathrm{r}=-0.417, P=0.27$; Exercise, $\mathrm{r}=0.546, P=0.13$. The correlations between the change in flow-mediated dilation and basal diameter from $0 \mathrm{~h}$ to $6.5 \mathrm{~h}$, were: Control, $\mathrm{r}=-$ $0.539, P=0.13$; Exercise, $\mathrm{r}=0.417, P=0.26$.

\section{$\underline{\text { Discussion }}$}

This is the first study to investigate the effect of a session of repeated sprints on postprandial endothelial dysfunction and triacylglycerol concentrations in adolescents. The main finding of the present study was that 40 maximal $6 \mathrm{~s}$ sprints, completed 14 hours prior to the consumption of a high-fat breakfast and high-fat lunch, attenuated the decline in flow-mediated dilation evident in a control trial in healthy adolescent boys. The prior session of $6 \mathrm{~s}$ sprints also lowered postprandial triacylglycerol concentrations, reducing the total and incremental area under the triacylglycerol concentration versus time curves by $13 \%$ and $15 \%$ respectively.

In the present study postprandial endothelial dysfunction was evident in the control trial following breakfast and lunch with flow-mediated dilation being reduced, compared to fasting, by 20 and $27 \%$ respectively. This state of endothelial 
dysfunction following consumption of high-fat meals has been shown previously in both adults (Gill et al., 2003; Gill et al., 2004; Tyldum et al., 2009) and adolescents (Sedgwick et al., 2013). In contrast when the adolescent boys in the present study completed the 40 maximal $6 \mathrm{~s}$ sprints 14 hours prior to the high-fat breakfast, postprandial endothelial dysfunction was not apparent, as there was no change in flow-mediated dilation compared to fasting. This finding is consistent with a previous study in adults that used high-intensity intermittent exercise (4 x 4 min cycle at 85 to $95 \%$ of maximum heart rate with each interspersed with 3 min cycle at 50 to $60 \%$ of maximum heart rate) which also found no evidence of endothelial dysfunction when exercise preceded consumption of a high fat meal (Tyldum et al., 2009). While exercise of a moderate intensity has also been shown to influence postprandial endothelial function in adults (Gill et al., 2003; Gill et al., 2004; Tyldum et al., 2009) and adolescents (Sedgwick et al., 2013) the beneficial effects may be more muted when the exercise intensity is moderate as these studies tended to only find an attenuation in the extent of postprandial endothelial dysfunction. While there may be some uncertainty as to whether high-intensity or repeated very short sprint exercise has a greater effect on postprandial endothelial function than moderate-intensity exercise, clearly the exercise model used in the present study was effective based on the flow-mediated dilation responses.

It has been recommended that flow-mediated dilation should be normalised to account for the post-occlusion shear stress stimulus (Pyke \& Tschakovsky, 2005) as this removes any association with basal diameter (Thijssen et al., 2008). In the present study normalised flow-mediated dilation was observed to decrease following the ingestion of the high-fat meals but, in contrast with the non-normalised findings, 
this decrease was not attenuated by the sprint exercise. Previous studies investigating the effect of continuous moderate-intensity and high-intensity intermittent exercise on postprandial flow-mediated dilation have reported attenuation in the postprandial decline in both flow-mediated dilation and normalised flow-mediated dilation (Sedgwick et al., 2013; Tyldum et al., 2009) but this was not the case in the present study. However, any conclusions based on the results of normalised flow-mediated dilation may need to be made cautiously, as the methods used to normalise flow-mediated dilation are currently under debate (Atkinson et al., 2009; McCully, 2012; Stoner, Tarrant, Fryer, \& Faulkner, 2013).

The reduction in triacylglycerol concentrations evident in the present study following the session of 40 maximal $6 \mathrm{~s}$ sprints is consistent with previous research in adults which has investigated the effect of sprint exercise on postprandial triacylglycerol concentrations. Four to five, $30 \mathrm{~s}$ maximal effort sprints, completed 14 to 18 hours prior to the consumption of a high-fat meal, were found to lower subsequent postprandial triacylglycerol concentrations in adults in two studies by $18 \%$ (Gabriel et al., 2012) and 21\% (Freese et al., 2011) but a third study observed no effect of sprint exercise (Tan, Mok, Yap, \& Burns, 2013). Maximum effort cycle sprints also seemed more effective at reducing postprandial triacylglycerol concentrations than moderate-intensity exercise (30 min brisk treadmill walking) (Gabriel et al., 2012). In previous studies in adolescents, moderate-intensity exercise has been reported to reduce the total area under the plasma triacylglycerol concentrations versus time curve by 8 to 22\% (Barrett et al., 2007; Lee et al., 2013; MacEneaney et al., 2009; Sedgwick et al., 2013; Tolfrey et al., 2008; Tolfrey et al., 2012) and high-intensity exercise (10 x 1 min run at 100\% peak oxygen uptake) by 11\% (Thackray, Barrett, \& 
Tolfrey, 2013). In the present study the corresponding reduction was $13 \%$, demonstrating that repeated bouts of very short (6s) maximal sprints are effective at reducing postprandial triacylglycerol concentrations. The reduction in postprandial triacylglycerol concentrations seen in the present study were similar to those observed by Thackray and colleagues (2013); despite the exercise time being much shorter in the present study (4 min vs. $10 \mathrm{~min}$ ). However it should be noted that the overall session time in the present study was much longer (90 min vs. $30 \mathrm{~min}$ ). These observed triacylglycerol concentration findings, and the flow-mediated dilation finding described above, support the assertion that repeated sprints of very short duration offer similar effects to moderate-intensity exercise.

Although this study did not directly measure the mechanisms through which sprint exercise may protect against postprandial endothelial dysfunction, it is known that measures of endothelial function, including flow-mediated dilation, are markers of nitric oxide bioavailability, where a decrease in nitric oxide bioavailability can result in a decline in flow-mediated dilation. It is believed that a transient rise in oxidative stress parallel to a rise in triacylglycerol concentrations following a high-fat meal induces postprandial endothelial dysfunction (Wallace et al., 2010) through the ability of free radicals to inactivate nitric oxide. Prior exercise may reduce the postprandial rise in oxidative stress by increasing the body's antioxidant capacity, consequently reducing the inactivation of nitric oxide, and so attenuating the decline in flow-mediated dilation (Tyldum et al., 2009). Such a mechanism could explain why high-intensity exercise may be more effective than moderate-intensity exercise at attenuating postprandial endothelial dysfunction as it has been shown, at least in 
adults, to illicit a greater total antioxidant capacity (Tyldum et al., 2009) and to attenuate the postprandial rise in oxidative stress (Gabriel et al., 2012).

Exercise involving repeated very short duration sprinting may lower postprandial triacylglycerol concentrations through a combination of increased triacylglycerolrich lipoprotein clearance from the circulation and a decreased hepatic secretion of very-low density lipoprotein-triacylglycerol (Gill \& Hardman, 2003; Maraki \& Sidossis, 2013). Prior exercise has been shown to increase skeletal muscle lipoprotein lipase activity, localised to the contracting muscles (Hamilton, Etienne, McClure, Pavey, \& Holloway, 1998), resulting in an increased hydrolysis and clearance of triacylglycerol from the bloodstream. The vigorous nature of contractions and the larger recruitment of muscle mass seen during sprint exercise may increase skeletal muscle lipoprotein lipase activity and explain why various sprinting regimens reduce postprandial triacylglycerol concentrations, despite the low energy expenditure. Sprint exercise is also associated with large increases in the concentrations of catecholamines and growth hormone (Kindermann et al., 1998; Stokes, 2003) which in turn are associated with increases in skeletal muscle lipoprotein lipase activity (Oscarsson, Ottosson, \& Eden, 1999; Pedersen, Bak, Holck, Schmitz, \& Richelsen, 1999). More recent evidence has also identified that exercise can reduce hepatic secretion of very-low density lipoprotein-triacylglycerol and alter the composition of very-low density lipoprotein particles, resulting in larger, more triacylglycerol-enriched very-low density lipoprotein particles (Alshayji, Caslake, \& Gill, 2012). This triacylglycerol enrichment of very-low density lipoprotein particles increases their affinity with lipoprotein lipase ultimately 
increasing their hydrolysis and triacylglycerol clearance from the circulation (Fisher, Coppack, Humphreys, Gibbons, \& Frayn, 1995).

Longer duration (e.g. $30 \mathrm{~s}$ ) repeated sprint protocols require high levels of motivation to complete and are often associated with feelings of nausea and lightheadedness (Richards et al., 2010). It was thought that the repeated $6 \mathrm{~s}$ sprints in the present study would be less likely to elicit these type of responses, and that the short intense bursts of activity associated with repeated short sprints might be more enjoyable and more appropriate for the young given their typical activity patterns, certainly when compared with moderate-intensity exercise (Crisp, Fournier, Licari, Braham, \& Guelfi, 2012). However, of the 15 recreationally active individuals who participated in the present study, 5 proved unable to tolerate the exercise pattern even though the sprints were only of $6 \mathrm{~s}$ duration. Typically these participants stopped exercising because they felt light-headed and nauseous; in 2 cases participants vomited. These responses occurred after only 7 (sd 2) sprints which suggests that some individuals cannot easily tolerate sprinting per se. It should be acknowledged that a low-intensity active recovery between the repeated sprints may be one method to increase tolerance to this type of sprint exercise, as it may reduce venous pooling in the legs and reduce feelings of light-headiness and nausea (Rakobowchuk et al., 2008), but this was not done in the present study in order to investigate the physiological effects of repeated short sprints alone. The tolerance to this type of sprint exercise may also be improved by reducing the length of each sprint (e.g. 3 s).

In conclusion the findings of the present study demonstrate that a session of 40 maximal effort $6 \mathrm{~s}$ sprints, completed 14 hours prior to the consumption of a high-fat 
breakfast and lunch, attenuated postprandial endothelial dysfunction and reduced postprandial triacylglycerol concentrations. This study is the first to demonstrate that exercise based on repeated very short duration sprints can elicit health benefits in adolescents; however, among some individuals, tolerance for this specific type of exercise may be poor. However, if short sprints could be incorporated into regularly undertaken activity/training programmes it is possible that health benefits could be gained. 


\section{References}

Al-Shayji, I. A., Caslake, M. J., \& Gill, J.M. (2012). Effects of moderate exercise on $\mathrm{VLDL}_{1}$ and intralipid kinetics in overweight/obese middle-aged men. American Journal of Physiology Endocrinology and Metabolism, 302, E349-E355. doi: 10.1152/ajpendo.00498.2011

Atkinson, G., Batterham, A. M., Black, M. A., Cable, N. T., Hopkins, N. D., Thijssen, D. H., ... Green, D. J. (2009). Is the ratio of flow-mediated dilation and shear rate a statistically sound approach to normalization in cross-sectional studies on endothelial function? Journal of Applied Physiology, 107, 1893-1899. doi: 10.1152/japplphysiol.00779.2009

Bansal, S., Buring, J. E., Rifai, N., Mora, S., Sacks, F. M., \& Ridker, P. (2007). Fasting compared with nonfasting triglycerides and risk of cardiovascular events in women. Journal of the American Medical Society, 298, 309-316. doi: 10.1001/jama.298.3.309

Baquet, G., Stratton, G., Van Praagh, E, \& Berthoin, S. (2007). Improving physical activity assessment in prepubertal children with high-frequency accelerometer monitoring: a methodological issue. Preventive Medicine, 44, 143-147, doi:10.1016/j.ypmed.2006.10.004

Barrett, L. A., Morris, J. G., Stensel, D. J., \& Nevill, M. E. (2006). Effect of intermittent games activity on postprandial lipemia in young adults. Medicine and 
Science in Sports and Exercise, 38, 1282-1287. doi:

10.1249/01.mss.0000227313.08599.b8

Barrett, L. A., Morris, J. G., Stensel D. J., \& Nevill, M. E. (2007). Exercise and postprandial plasma triacylglycerol concentrations in healthy adolescent boys. Medicine and Science in Sports and Exercise, 39, 116-122. doi:

10.1249/01.mss.0000240327.31276.18

Borg, G. A. (1973). Perceived exertion: a note on "history" and methods. Medicine and Science in Sports and Exercise, 5, 90-3.

Crisp, N. A., Fournier, P. A., Licari, M. K., Braham, R., \& Guelfi, K. J. (2012). Adding sprints to continuous exercise at the intensity that maximises fat oxidation: implications for acute energy balance and enjoyment. Metabolism, 61, 1280-1288. doi: 10.1016/j.metabol.2012.02.009

Fisher, R. M., Coppack, S. W., Humphreys, S. M., Gibbons, G. F., \& Frayn, K. N. (1995) Human triacylglycerol-rich lipoprotein subfractions as substrates for lipoprotein lipase. Clinica Chimica Acta, 236, 7-17. doi: 10.1016/00098981(95)06032-3

Freedson, P. S., Sirard, J., Debold, E. Pate, R., Dowda, M., Trost, S., \& Sallis J (1997). Calibration of the Computer Science and Applications, Inc. (CSA) accelerometer. Medicine and Science in Sports and Exercise, 29, S45. 
Freese, E. C., Levine, A. S., Chapman, D. P., Hausman, D. B., \& Cureton, K. J. (2011). Effects of acute sprint interval cycling and energy replacement on postprandial lipemia. Journal of Applied Physiology, 111, 1584-1589. doi: 10.1152/japplphysiol.00416.2011

Gabriel, B., Ratkevicius, A., Gray, P., Frenneaux, M. P., \& Gray, S. R. (2012). Highintensity exercise attenuates postprandial lipaemia and markers of oxidative stress. Clinical Science, 123, 313-321. doi: 10.1042/CS20110600

Gibala, M. J., Little, J. P., MacDonald, M. J., \& Hawley, J. A. (2012). Physiological adaptations to low-volume, high-intensity interval training in health and disease. Journal of Physiology, 590, 1077-1084. doi: 10.1113/jphysiol.2011.224725

Gill, J. M., Al-Mamari, A., Ferrell, W. R., Cleland, S. J., Packard, C. J., Sattar, N., ... Caslake, M. J. (2004). Effects of prior moderate exercise on postprandial metabolism and vascular function in lean and centrally obese men. Journal of the American College of Cardiology, 44, 2375-2382. doi: 10.1016/j.jacc.2004.09.035

Gill, J. M., Caslake, M. J., McAllister, C., Tsofliou, F., Ferrell, W. R., Packard, C. J., \& Malkova, D. (2003). Effects of short-term detraining on postprandial metabolism, endothelial function, and inflammation in endurance trained men: dissociation between changes in triglyceride metabolism and endothelial function. Journal of Clinical Endocrinology and Metabolism, 88, 4328-4335. doi: 10.1210/jc.2003030226 
Gill, J. M., \& Hardman, A. E. (2003). Exercise and postprandial lipid metabolism: an update on potential mechanisms and interactions with high-carbohydrate diets (review). Journal of Nutritional Biochemistry, 14, 122-134. doi: 10.1016/S09552863(02)00275-9

Hamilton, M. T., Etienne, J., McClure, W. C., Pavey, B. S., \& Holloway, A. K. (1998). Role of local contractile activity and muscle fiber type on LPL regulation during exercise. American Journal of Physiology Endocrinology and Metabolism, 275, E1016-E1022. doi: 0193-1849/98

Harris, R. A., Nishiyama, S. K., Wray, D. W., \& Richardson, R. S. (2010). Ultrasound assessment of flow-mediated dilation. Hypertension, 55, 1075-1085. doi: 10.1161/HYPERTENSIONAHA.110.150821

Juonala, M., Viikari, J. S., Laitinen, T., Marniemi, J., Helenius, H., Ronnemaa, T., \& Raitakari, O. T. (2004). Interrelations between brachial endothelial function and carotid intima-media thickness in young adults: the cardiovascular risk in young Finns study. Circulation, 110, 2918-2923. doi:

10.1161/01.CIR.0000147540.88559.00

Kindermann, W., Schnabel, A., Schmitt, W. M., Biro, G., Cassens, J., \& Weber, F. (1982). Catecholamines, growth hormone, cortisol, insulin and sex hormone in anaerobic and aerobic exercise. European Journal of Applied Physiology, 49, 389399. doi: 10.1007/BF00441300 
Lee, S., Burns, S. F., Kuk, J. L., \& Arslanian, S. (2013). Effects of acute exercise on postprandial triglyceride response after a high-fat meal in overweight black and white adolescents. International Journal of Obesity, 37, 966-971. doi: 10.1038/ijo.2013.29

MacEneaney, O. J., Harrison, M., O'Gorman, D. J., Pankratieva, E. V., O’Connor, P. L., \& Moyna, N. M. (2009). Effect of prior exercise on postprandial lipemia and markers of inflammation and endothelial activation in normal weight and overweight adolescent boys. European Journal of Applied Physiology, 106, 721-729. doi: 10.1007/s00421-009-1073-y

Magnussen, C. G., Niinikoski, H., Juonala, M., Kivimaki, M., Ronnemaa, T., Viikari, J. S., ... Raitakari, O. T. (2012). When and how to start prevention of atherosclerosis? Lessons from the Cardiovascular Risk in the Young Finns Study and the Special Turku Coronary Risk Factor Intervention Project. Pediatric Nephrology, 27, 1441-1452. doi: 10.1007/s00467-011-1990-y

Maraki, M. I., \& Sidossis, L. S. (2013). The latest on the effect of prior exercise on postprandial lipaemia. Sports Medicine, 43, 463-481. doi: 10.1007/s40279-0130046-9

Matthews, D. R., Hosker, J. P., Rudenski, A. S., Naylor, B. A., Treacher, D. F., \& Turner, R. C. (1985). Homeostasis model assessment: insulin resistance and beta-cell function from fasting plasma glucose and insulin concentrations in man.

Diabetologia, 28, 412-419. doi: 10.1007/BF00280883 
McCully, K. K. (2012). Flow-mediated dilation and cardiovascular disease. Journal of Applied Physiology, 112, 1957-1958. doi: 10.1152/japplphysiol.00506.2012

Oscarsson, J., Ottosson, M., \& Eden, S. (1999). Effects of growth hormone on lipoprotein lipase and hepatic lipase. Journal of Endocrinological Investigation, 22, 2-9. retrieved from http://www.jendocrinolinvest.it/jei/en/

Pedersen, S. B., Bak, J. F., Holck, P., Schmitz, O., \& Richelsen, B. (1999). Epinephrine stimulates human muscle lipoprotein lipase activity in vivo. Metabolism, 48, 461-464. doi: 10.1016/S0026-0495(99)90104-X

Petitt, D. S., \& Cureton, K. J. (2003). Effects of prior exercise on postprandial lipemia: a quantitative review. Metabolism, 52, 418-424. doi:

$10.1053 /$ meta.2003.50071

Pyke, K. E., \& Tschakovsky, M. E. (2005). The relationship between shear stress and flow-mediated dilatation: implications for the assessment of endothelial function. Journal of Physiology, 568, 357-369. doi: 10.1113/jphysiol.2005.089755

Rakobowchuk, M., Tanguay, S., Burgomaster, K. A., Howarth, K. R., Gibala, M. J., \& MacDonald, M. J. (2008). Sprint interval and traditional endurance training induce similar improvements in peripheral arterial stiffness and flow-mediated dilation in healthy humans. American Journal of Physiology Regulatory, Intergrative and Comparative Physiology, 295, R236-242. doi: 10.1152/ajpregu.00069.2008 
Ratel, S., Duche P, \& Williams C. A. (2006). Muscle fatigue during high-intensity exercise in children. Sports Medicine, 36, 1031-1065. doi:10.2165/00007256200636120-00004

Richards, J. C., Johnson, T. K., Kuzma, J. N., Lonac, M. C., Schweder, M. M., Voyles, W. F., \& Bell, C. (2010). Short-term sprint interval training increases insulin sensitivity in healthy adults but does not affect the thermogenic response to betaadrenergic stimulation. Journal of Physiology, 588, 2961-2972. doi: 10.1113/jphysiol.2010.189886

Sedgwick, M. J., Morris, J. G., Nevill, M. E., Tolfrey, K., Nevill, A., \& Barrett, L. A. (2013). Effect of exercise on postprandial endothelial function in adolescent boys. British Journal of Nutrition, 110, 301-309. doi: 10.1017/S0007114512004977

Stokes, K. (2003). Growth hormone response to sub-maximal and sprint exercise. Growth Hormone and IGF Research, 13, 225-238. doi:10.1016/S10966374(03)00016-9

Stone, M. R., Rowlands, A. V., Middlebrooke, A. R., Jawis, M. N., \& Eston, R. G. (2009). The pattern of physical activity in relation to health outcomes in boys. International Journal of Pediatric Obesity, 4, 306-315. doi: $10.3109 / 17477160902846179$ 
Stone, M. R., Rowlands, A. V., \& Eston, R.G. (2009). Characteristics of the activity pattern in normal weight and overweight boys. Preventive Medicine, 49, 205-208. doi: 10.1016/j.ypmed.2009.06.012

Stoner, L., Tarrant, M. A., Fryer, S. \& Faulkner, J. (2013). How should flowmediated dilation be normalized to its stimulus? Clinical Physiology and Functional Imaging, 33, 75-78. doi: 10.1111/j.1475-097X.2012.01154.X

Tan, M. S., Mok, A., Yap, M. C., \& Burns, S. F. (2013). Effect of sprint interval versus continuous cycling on postprandial lipaemia. Journal of Sports Sciences, 31, 989-995. doi: 10.1080/02640414.2012.759661

Tanner, J. M. (1989). Foetus into man: Physical growth from conception to maturity. Ware, UK: Castlemead Publications.

Taveras, E. M., Berkey, C. S., Rifas-Shiman, S. L., Ludwig, D. S., Rockett, H. R., Field, A. E., ... Gillman, M. W. (2005). Association of consumption of fried food away from home with body mass index and diet quality in older children and adolescents. Pediatrics, 116, e518-e524. doi: 10.1542/peds.2004-2732

Thackray, A. E., Barrett, L. A., \& Tolfrey, K. (2013). Acute high-intensity interval running reduces postprandial lipemia in boys. Medicine and Science in Sports and Exercise, 45, 1277-1284. doi: 10.1249/MSS.0b013e31828452c1 
Thijssen, D. H., Dawson, E. A., Black, M. A., Hopman, M. T., Cable, N. T., \& Green, D. J. (2008). Heterogeneity in conduit artery function in humans: impact of arterial size. American Journal of Physiology Heart and Circulatory Physiology, 295, H1927-H1934. doi: 10.1152/ajpheart.00405.2008

Tolfrey, K., Bentley, C., Goad, M., Varley, J., Willis, S., \& Barrett, L. (2012). Effect of energy expenditure on postprandial triacylglycerol in adolescent boys. European Journal of Applied Physiology, 112, 23-31. doi: 10.1007/s00421-011-1936-x

Tolfrey, K., Doggett, A., Boyd, C., Pinner, S., Sharples, A., \& Barrett, L. (2008). Postprandial triacylglycerol in adolescent boys: a case for moderate exercise. Medicine and Science in Sports and Exercise, 40, 1049-1056. doi: 10.1249/MSS.0b013e31816770fe

Tyldum, G. A., Schjerve, I. E., Tjonna, A. E., Kirkeby-Garstad, I., Stolen, T. O., Richardson, R. S., \& Wisloff, U. (2009). Endothelial dysfunction induced by postprandial lipemia: complete protection afforded by high-intensity aerobic interval exercise. Journal of the American College of Cardiology, 53, 200-206. doi: 10.1016/j.jacc.2008.09.033

Wallace, J. P., Johnson, B., Padilla, J., \& Mather, K. (2010). Postprandial lipaemia, oxidative stress and endothelial function: a review. International Journal of Clinical Practice, 64, 389-403. doi: 10.1111/j.1742-1241.2009.02146.x 
Yeboah, J., Folsom, A. R., Burke, G. L., Johnson, C., Polak, J. F., Post, W., ... Herrington, D. M. (2009). Predictive value of brachial flow-mediated dilation for incident cardiovascular events in a population-based study: the multi-ethnic study of atherosclerosis. Circulation, 120, 502-509. doi: 10.1161/CIRCULATIONAHA 


\section{Tables and Illustrations}

Table 1: Physical characteristics of participants

\begin{tabular}{lc}
\hline Age (years) & $13.1(0.6)$ \\
Height $(\mathrm{m})$ & $1.59(0.08)$ \\
Body mass $(\mathrm{kg})$ & $49.7(9.8)$ \\
BMI $\left(\mathrm{kg} \cdot \mathrm{m}^{-2}\right)$ & $19.4(2.3)$ \\
Sum of four skin folds $(\mathrm{mm})^{*}$ & $45.2(12.9)$ \\
Waist circumference $(\mathrm{cm})$ & $70.9(7.6)$ \\
Hip circumference $(\mathrm{cm})$ & $86.4(8.2)$
\end{tabular}

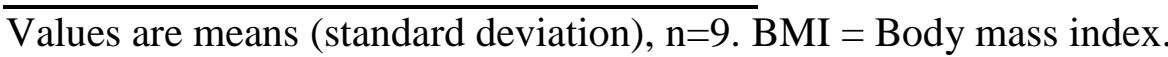

* Four skinfold sites were biceps, triceps, subscapular and suprailiac. 
Table 2. Accelerometer wear time, activity counts and time spent in low-, moderate- and vigorous-intensity physical activity during the day before the main trials (day 0) and day 1 of the main trials

\begin{tabular}{|c|c|c|c|c|c|c|}
\hline & Day & Control & Exercise & $P^{*}$ & $\mathrm{ES}$ & $\bar{X}_{\text {exercise-control }}(95 \% \mathrm{CI})$ \\
\hline Wear time & 0 & $789(34)$ & $758(67)$ & 0.40 & 0.22 & $-31(-250$ to 188$)$ \\
\hline$(\min )$ & 1 & $773(53)$ & $651(39)$ & 0.08 & 0.99 & $-121(-492$ to 250$)$ \\
\hline Total counts & 0 & $2.59(0.18)$ & $2.69(0.36)$ & 0.82 & 0.14 & $0.11(-2.85$ to 3.07$)$ \\
\hline (counts)\# & 1 & $3.23(0.50)$ & $2.76(0.32)$ & 0.10 & 0.43 & $-0.47(-2.06$ to 1.12$)$ \\
\hline Time averaged counts & 0 & $331(25)$ & $396(94)$ & 0.50 & 0.36 & $65(-524$ to 653$)$ \\
\hline$\left(\right.$ counts $\left.\cdot \min ^{-1}\right)$ & 1 & $422(57)$ & $442(66)$ & 0.71 & 0.12 & 19 (-298 to 336$)$ \\
\hline Low-intensity & 0 & $113(7)$ & $106(15)$ & 0.61 & 0.24 & $-7(-92$ to 78$)$ \\
\hline$(\min )$ & 1 & $113(10)$ & $99(12)$ & 0.32 & 0.47 & $-14(-95$ to 67$)$ \\
\hline Moderate-intensity & 0 & $60(9)$ & $54(7)$ & 0.64 & 0.28 & $-6(-85$ to 73$)$ \\
\hline$(\min )$ & 1 & $65(9)$ & $54(7)$ & 0.07 & 0.54 & $-11(-43$ to 21$)$ \\
\hline Vigorous-intensity & 0 & $8(1)$ & $12(4)$ & 0.40 & 0.51 & $4(-25$ to 34$)$ \\
\hline$(\min )$ & 1 & $16(5)$ & $14(4)$ & 0.65 & 0.15 & $-2(-25$ to 21$)$ \\
\hline
\end{tabular}

Values are means (standard error of the means) unless stated, $\mathrm{n}=7 . \mathrm{ES}=$ Effect size, $\overline{\boldsymbol{X}}_{\text {exercise-control }}(95 \% \mathrm{CI})=\mathrm{Mean}$ and $95 \%$ Confidence interval of difference between control and exercise trial (exercise - control). * Paired Student's t-test. \# Counts in 100,000's. 
Table 3. Basal diameter and peak diameter of the brachial artery during the measurement of flow-mediated dilation in the control and exercise trials

\begin{tabular}{|c|c|c|c|c|c|c|}
\hline & & Control & & & Exercise & \\
\hline & $0 \mathrm{~h}$ & $3 \mathrm{~h}$ & $6.5 \mathrm{~h}$ & $0 \mathrm{~h}$ & $3 \mathrm{~h}$ & $6.5 \mathrm{~h}$ \\
\hline Basal diameter $(\mathrm{mm}) \dagger+$ & 3.33 & 3.47 & 3.45 & 3.28 & 3.39 & 3.44 \\
\hline & $(0.11)$ & $(0.10)$ & $(0.11)$ & $(0.11)$ & $(0.10)$ & $(0.11)$ \\
\hline Peak diameter $(\mathrm{mm}) \dagger t$ & 3.60 & 3.70 & 3.66 & 3.54 & 3.66 & 3.70 \\
\hline & $(0.13)$ & $(0.13)$ & $(0.13)$ & $(0.14)$ & $(0.13)$ & $(0.13)$ \\
\hline Values are means (standar & rror of $\mathrm{t}$ & means), & $=9$. Dat & vas anal & sed using & mixed \\
\hline effects general linear moc & with ty & fixed fa & ors (tri & and time & and on & andom \\
\hline factor (participant): for $b$ & l diame & r: main & fect tria & $P=0.21$ & main eff & t time, \\
\hline$P<0.001$; interaction effec & trial $x$ ti & $\mathrm{e}, P=0.1$ & ; and for & eak dia & leter: ma & effect \\
\hline trial, $P=0.61 ;$ main effect $\mathrm{t}$ & le, $P=0 . \mathrm{C}$ & 2 ; intera & ion effec & rial $x$ tin & $P=0.05$ & . Least \\
\hline significant differences was & sed to ic & ntify wh & e signif & nt main & ffects la & \\
\hline$\dagger$ post-hoc analysis on ma & ffect of & me: Di & ence $b$ & een 01 & nd $3 \mathrm{~h}$ & 0.05 . \\
\hline
\end{tabular}


(a)

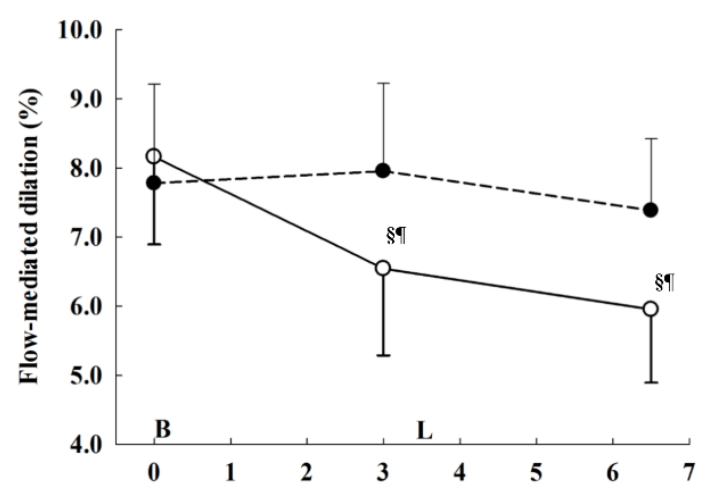

(b)

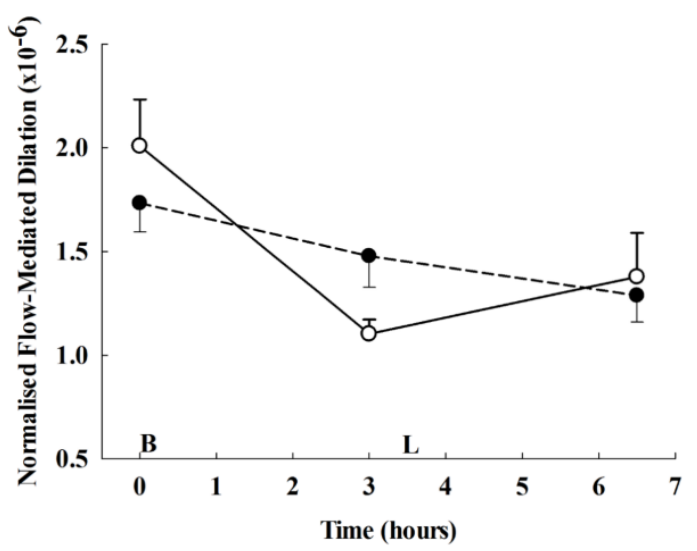

Figure 1. (a) Flow-mediated dilation and (b) normalised flow-mediated dilation. B, breakfast; L, lunch. Values are means, with their standard errors represented by vertical bars $(n=9)$. Data were analysed using a mixed-effects general linear model with two fixed factors (trial and time) and one random factor (participant). Least significant differences post-hoc analysis was used to identify where significant main effects lay and when a significant time $\mathrm{x}$ trial interaction was identified, pre-specified planned comparisons were used, specifically, comparisons within trial with respect to the fasting measure and between trials at the same time point. (a) Flow-mediated dilation: main effect trial, $P=0.012$; main effect time, $P=0.004$; interaction effect trial $\mathrm{x}$ time, $P=0.003$. (b) Normalised flow-mediated dilation: main effect trial, $P=0.97$; main effect time, $P=0.001$; interaction effect trial $\mathrm{x}$ time, $P=0.08)$. $\S$ post-hoc analysis on interaction effect of trial $\mathrm{x}$ time - different from $0 \mathrm{~h}$ in the same trial, $P<0.05$ ( $3 \mathrm{~h}$ : $P=0.003, \mathrm{ES}=0.43, \overline{\boldsymbol{X}}_{\text {control } 3 \mathrm{~h}-\text { control } 0 \mathrm{~h}}(95 \% \mathrm{CI})=-1.62(-4.28$ to 1.04$) \%$, and $6.5 \mathrm{~h}$ : $P=0.003, \mathrm{ES}=0.63, \overline{\boldsymbol{X}}_{\text {control } 6.5 \mathrm{~h}-\text { control oh }}(95 \% \mathrm{CI})=-2.21$ ( -5.75 to 1.33$\left.) \%\right)$; II post-hoc analysis on interaction effect of trial $\mathrm{x}$ time - different from exercise trial at same time point, $P<0.05$ (3 h: $P=0.002, \mathrm{ES}=0.37, \overline{\boldsymbol{X}}_{\text {exercise-control }}(95 \% \mathrm{CI})=1.41(-0.70$ to 3.52$) \%$, and $6.5 \mathrm{~h}: P=0.002, \mathrm{ES}=0.45, \overline{\boldsymbol{X}}_{\text {exercise-control }}(95 \% \mathrm{CI})=1.43(-0.69$ to 3.55$\left.) \%\right)$

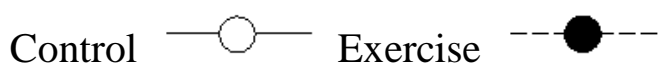



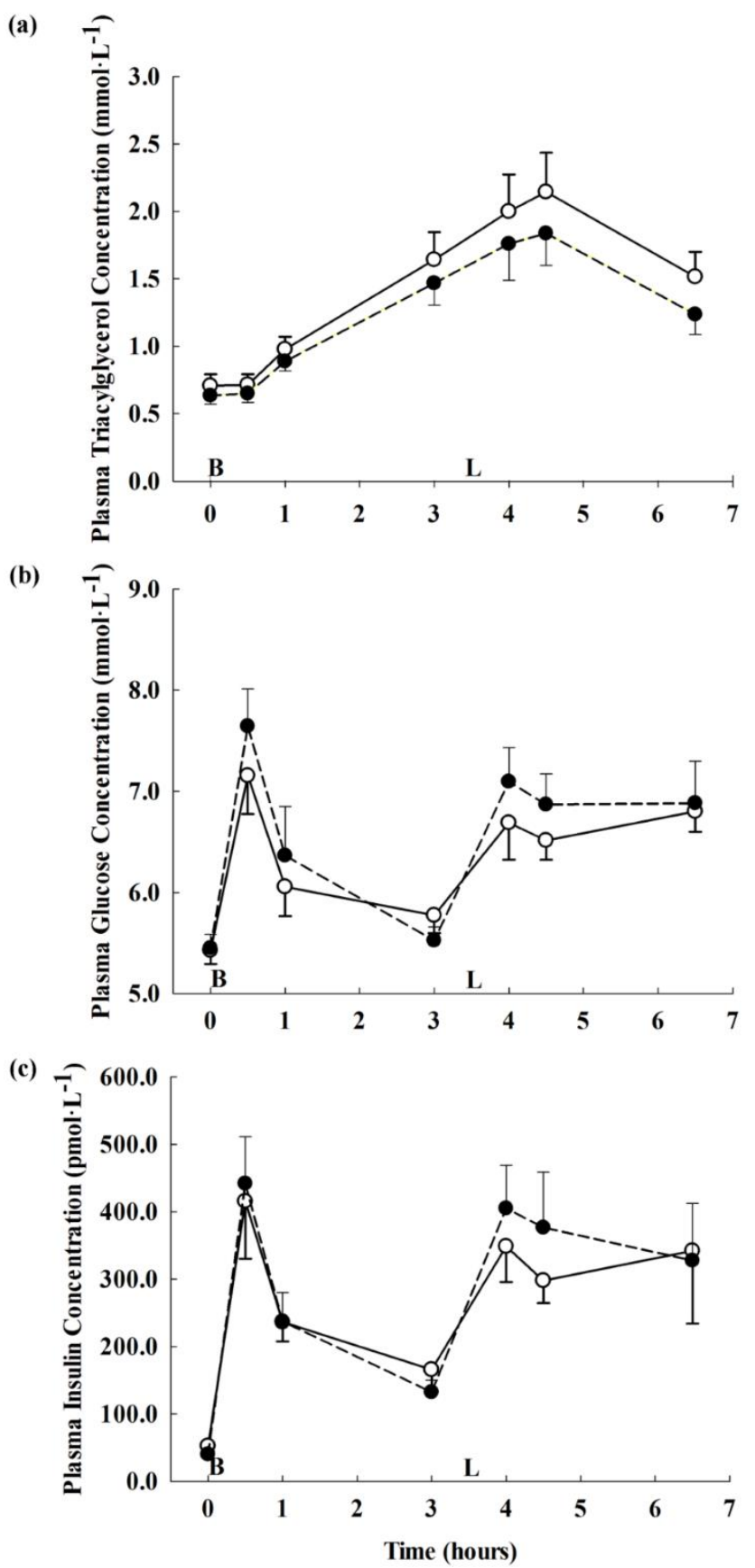

Figure 2. Plasma (a) Triacylglycerol (b) glucose (c) insulin concentrations. B, breakfast; L, lunch. Values are means, with their standard errors represented by vertical bars $(n=9)$. Data were analysed using a mixed-effects general linear model with two fixed factors (trial and time) and one random factor (participant). Least significant differences post-hoc analysis was used to identify where significant main effects lay; triacylglycerol data were Ln transformed prior to the analysis. (a) Triacylglycerol: main effect trial, $P=0.019$; main effect time, $P<0.001$; interaction effect trial $\mathrm{x}$ time, $P=0.07$. (b) Glucose: main effect trial, $P=0.12$; main effect time, $P<0.001$; interaction effect trial $\mathrm{x}$ time, $P=0.39$. (c) Insulin: main effect trial, $P=0.27$; main effect time, $P=0.001$; interaction effect trial $\mathrm{x}$ time, $P=0.49$.

Control $\longrightarrow-$ Exercise --- 